\title{
Failure analysis on lattice matched GalnP/Ga(In)As/Ge commercial concentrator solar cells after temperature accelerated life tests
}

\author{
Vincenzo Orlando , Mercedes Gabás , Beatriz Galianā , Pilar Espinet-González , \\ Santiago Palanco , Neftali Nuñez , Manuel Vázquez , Kenji Araki and Carlos Algora
}

\begin{abstract}
Accelerated life tests are frequently used to provide reliability information in a moderate period of time (weeks or months), and after that, a failure analysis is compulsory to detect the failure origins. In this paper, a failure analysis has been carried out after a temperature accelerated life test on lattice matched $\mathrm{GaInP} / \mathrm{Ga}(\mathrm{In}) \mathrm{As} / \mathrm{Ge}$ triple junction commercial solar cells. Solar cells were forward biased in darkness inside three climatic chambers in order to emulate the photo-generated current under nominal working conditions (a concentration level of 820 suns). After the accelerated aging test, a characterization of the resulting cells by means of quantum efficiency, dark and illumination I-V curves, electroluminescence, scanning electron microscope, energy dispersive X-ray, scanning transmission electron microscope and X-ray photoelectron spectroscopy has been carried out.

Current is identified as the cause of degradation while temperature just dominates the accelerating factor of the aging test. Current promotes the front metal damage produced by the chemical evolution of the electroplating impurities together with those of the tab soldering process. Semiconductor structure does not seem to be responsible of any failure. Therefore, this kind of lattice matched $\mathrm{GaInP/Ga(In)As/Ge} \mathrm{triple} \mathrm{junction} \mathrm{solar} \mathrm{cells,} \mathrm{that} \mathrm{as} \mathrm{of} 2016$, are the workhorse of CPV technology, exhibits as a very robust device if the front metal connection is properly accomplished.
\end{abstract}

KEYWORDS

CPV; failure analysis; reliability; accelerated life test; characterization

\section{INTRODUCTION}

Concentration photovoltaics (CPV) sets out open questions about its reliability because, in many cases, CPV systems are still in the prototyping and testing phases. Reliability data collection has only begun since 2005 running into commercial development, with the exception of a few multiple-hundred kilowatt scale plants. Therefore, CPV lacks a long term (namely 25-30 years) historical record of proven longevity and reliability although the existing data show no detectable degradation in well-designed CPV plants [1]. Furthermore, reliability is a key aspect for an effective CPV cost reduction.
In the case of concentrator solar cells, several degradation analyses have been carried out after onsun exposure of some months. The failures observed in these tests were mainly attributed to thermal runaway $[2,3]$. These failures have been considered as infant mortality, because they appeared in the early life of the CPV modules, and only in some solar cells [4]. A review of the degradation tests can be found in [1].

In spite of the interest of these on field studies, they cannot supply the expected performance after the expected lifetime. This is why accelerated life tests (ALT) are used to provide reliability information in a moderate period of time (weeks or months). In a previous work [5], we 
described the approach, design, setup, progress and reliability results obtained from the temperature ALT, carried out on 45 commercial lattice-matched $\mathrm{GaInP} / \mathrm{Ga}(\mathrm{In}) \mathrm{As} / \mathrm{Ge}$ triple junction solar cells. These commercial solar cells were intended to be placed inside CPV modules designed to work at 820 suns at a nominal temperature of $80^{\circ} \mathrm{C}$ [5]. By using the Arrhenius-Weibull model, the main reliability functions (probability density function, reliability, unreliability and instantaneous failure rate) and parameters (warranty time, MTTF, i.e. mean time to failure) were obtained. That work showed that this kind of solar cells, assuming an average operation of $5 \mathrm{~h} /$ day and a temperature of $80^{\circ} \mathrm{C}$, have a probability of failure after 25 years of operation of $0.1 \%$ and a warranty time for a failure population of $5 \%$ of 113 years. These data have to be filtered for the solar cell operation at a real place (irradiance, temperature distribution, wind velocity, etc.) in order to know the real life time. This task is now underway in our group.

The same work [5] showed Arrhenius activation energy of $1.59 \mathrm{eV}$, which is similar to those obtained in optoelectronic devices. The remaining stage of that ALT is to carry out a failure analysis to determine what causes the failures in the solar cells. This kind of work, to our knowledge, has never been carried out on concentrator triple junction concentrator solar cells, and is the objective of this paper.

\section{EXPERIMENTAL}

In order to have a global view of the whole reliability analysis procedure, in this section, we summarize the key aspects of the temperature ALT described in [5] as well as the specific actions accomplished for the failure analysis study.

Before carrying out the temperature ALT, 45 solar cells were carefully characterized by means of dark and light (1 $\times$ and $820 \times$ ) I-V curves, external quantum efficiency
(EQE), electroluminescence (EL) mapping and X-ray imaging. These measurements will serve as a reference when carrying out the post-degradation characterization once the ALT finishes.

The temperature ALT was carried out in three climatic chambers (15 solar cells in each chamber), set to three different temperatures. The junction temperature $\left(\mathrm{T}_{\text {cell }}\right)$ of the solar cells for each chamber was 119,126 and $164^{\circ}$ C. To precisely measure the junction temperature, we proceed as follows: thermal finite element analysis simulations were carried out to obtain an approximate junction temperature under the injected current. After that the $\mathrm{dV} / \mathrm{dT}$ of several solar cells was obtained using a high speed/high resolution voltmeter, and the average value of the $\mathrm{dV} / \mathrm{dT}$ was used to obtain the junction temperature from the voltage measured under constant current forward bias. The method is further explained in $[5,6]$.

The solar cells were forward biased in darkness inside the climatic chambers in order to emulate the photogenerated current under nominal working conditions (concentration level). The suitability to use forward bias current to emulate the photogenerated current is explained in [7]. An intensity of the injected current of $3.2 \mathrm{~A}$ (the active area of the solar cells was $0.49 \mathrm{~cm}^{2}$ ) was determined by using our $3 \mathrm{D}$ distributed model in order to avoid an electrical overstress that would produce artificial failures, unexpected on real working conditions [5]. By assuming that the front metal grid is equipotential, the current was injected on one of the buses while voltage was measured on the other busbar (see Figure 1). Dark I-V curve was measured on each cell (using the four point probe method in order to circumvent series resistance effects) every two hours in order to have a good tracking of the solar cell degradation. Besides, chamber temperature and solar cell voltage (V in Figure 1) - from which the solar cell temperature can be determined - were logged every five minutes to ensure that the temperature test conditions were constant.

Three of the solar cells in each chamber were not under forward biasing (no current injection) to be used as
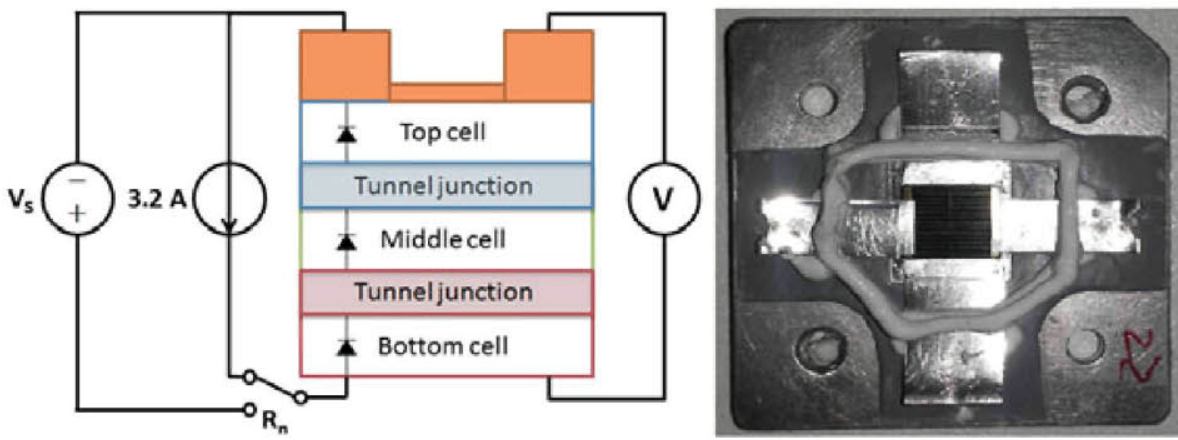

Figure 1. (a) Schematic of the current injection/measurement connections on the solar cells (left): Rn represents the relay used to switch between the current injection and the I-V curve measurement electronics. VS represents the Agilent $6631 \mathrm{~B}$ power supply, and $V$ represents the Keithley 3706A digital multimeter (DMM) used to measure the I-V curve of the solar cells every $2 \mathrm{~h}$. ID represents the constant current source used to carry out the degradation of the solar cells, which for this test was set to $3.2 \mathrm{~A}$. Before changing the state of the relay, the power supply and current source were turned off to prevent current spikes. Each of the solar cells in the system was connected this way. (b) Picture of a $\mathrm{CoC}$ (Cell on Carrier) before testing (right). 
"reference" solar cells. In one of the three reference cells per chamber, its I-V curve was only measured at the beginning and the end of the whole test. The purpose of this cell is to analyze only the effects of temperature excluding the influence of current biasing and I-V curve measurements. Therefore, there are three of these reference cells and are called as "Ref_Low", "Ref_Mid" and "Ref_High" in Table I.

Concerning the other two reference solar cells (per chamber), their I-V curve was measured at the same intervals as the rest of the degraded solar cells (every two hours). The purpose of these two reference cells was to analyze the effects of I-V curve measurements, specifically to check if measuring the I-V curve would cause any kind of degradation such as electrostatic discharge (ESD) [3]. Once we checked that the I-V measurements did not cause any kind of degradation on these reference cells, they will not be mentioned anymore from now on.

The characteristic dark I-V curve evolution of the solar cells with current injection during the ALT at the three climatic chamber temperatures is gathered in Figure 2. As it can be observed, all failures were catastrophic. The typical evolution of the dark I-V curves goes through small changes in shunt resistance (curve (a)), followed by a sudden loss of voltage (curve (b)), which evolves until a short circuit-like performance (curve (c)).

The ALT was stopped once most of the solar cells had completely failed meaning that they transitioned from curves (a) to (c) - but some cells still remain at curve (b) (see Figure 2). This was done to have a few solar cells degraded but not completely shunted, in order to investigate their state before failure. After the ALT finished, the cells were again characterized by means of dark and light $\mathrm{I}-\mathrm{V}$ curves, EQE and EL. As expected from the short-circuitlike performance, none of these measurements produced results, except for the solar cells that had not reached the final failure state, namely those in the state (b).

In order to determine the origin of failures of the solar cells, several ones (see Table I) were selected for an extensive material characterization before and after the ALT, namely scanning electron microscopy (SEM), transmission electron microscopy (TEM), energy-dispersive X-ray spectroscopy (EDX) and X-ray photoelectron spectroscopy (XPS).

The bus surface chemical composition analysis through XPS was carried out in a Thermo Scientific Multilab 2000 spectrometer, fitted with a dual anode $(\mathrm{Mg}-\mathrm{K} \alpha, \mathrm{A} 1-\mathrm{K} \alpha)$ $\mathrm{X}$-ray source and a $110-\mathrm{mm}$ mean radius hemispherical sector analyzer. No $\mathrm{Ar}^{+}$sputtering was made to clean up sample surfaces, which were measured as received. The core level spectra were fitted using the XPSPeak software package [8].

The solar cell front metal grid evolution was monitored using SEM. Planar view and cross-section images of several degraded and non-degraded solar cells were taken with a FEI Helios Nanolab 650 Dual Beam microscope, fitted with a Schottky field emission source for SEM (FESEM) and a Tomahawk focused ion beam (FIB), which allows a precise and reliable milling and patterning. Different areas of the cells were analyzed by preparing cross section using FIB milling (at $30 \mathrm{kV}$ and 65-9.4 nA). In these cases, the cell surface was previously protected by a cord of platinum deposited using a gas injection system. EDX was performed in several planar view and cross-section cell areas, including the metallization grid and the busbars, to monitor their chemical composition. Additionally, the chemical composition of the semiconductor layers was also studied by means of EDX analysis and scanning TEM (STEM) with a high-angle annular dark-field imaging HAADF detector for Z-contrast images installed in a Philips Tecnai 20F FEG transmission electron microscope.

\section{FAILURE ANALYSIS: RESULTS AND DISCUSSION}

In the next subsections, the effect of only temperature (section 3.2), and the combination of current injection together with temperature (section 3.3) on the degradation process, will be analyzed with the aim of discussing the cause(s) of the failures observed. First, the characterization

Table I. Nomenclature used on the solar cells analyzed by material characterization techniques before and after ALT. Tcell is higher than climatic chamber temperature in degraded cels as a consequence of current injection heating.

\begin{tabular}{|c|c|c|c|}
\hline $\begin{array}{l}\text { Solar cell } \\
\text { nomenclature }\end{array}$ & $\begin{array}{l}\text { Climatic chamber } \\
\text { temperature }\left({ }^{\circ} \mathrm{C}\right)\end{array}$ & $\begin{array}{l}\mathrm{T}_{\text {cell }} \\
\left({ }^{\circ} \mathrm{C}\right)\end{array}$ & Description \\
\hline Ref_Low & 80 & 80 & Reference solar cell in the $119^{\circ} \mathrm{C}$ test \\
\hline Ref_Mid & 114 & 114 & Reference solar cell in the $126^{\circ} \mathrm{C}$ test \\
\hline Ref_High & 144 & 144 & Reference solar cell in the $164^{\circ} \mathrm{C}$ test \\
\hline Deg_Low & 80 & 119 & Degraded solar cell with current injection tested at $119^{\circ} \mathrm{C}$ \\
\hline Deg_Mid & 114 & 126 & Degraded solar cell with current injection tested at $126^{\circ} \mathrm{C}$ \\
\hline Deg_High & 144 & 164 & Degraded solar cell with current injection tested at $164{ }^{\circ} \mathrm{C}$ \\
\hline $\begin{array}{l}\text { Deg_Low_S (I) } \\
\text { Deg_Low_S (II) }\end{array}$ & 80 & 119 & $\begin{array}{l}\text { Degraded solar cells with current injection disconnected from the current source } \\
\text { once they reached the (b) curve (Figure 2). }\end{array}$ \\
\hline Deg_Mid_OK & 114 & 126 & $\begin{array}{l}\text { Degraded solar cell with current injection that remains at the (b) curve (Figure 2) } \\
\text { when the ALT was stopped. }\end{array}$ \\
\hline
\end{tabular}



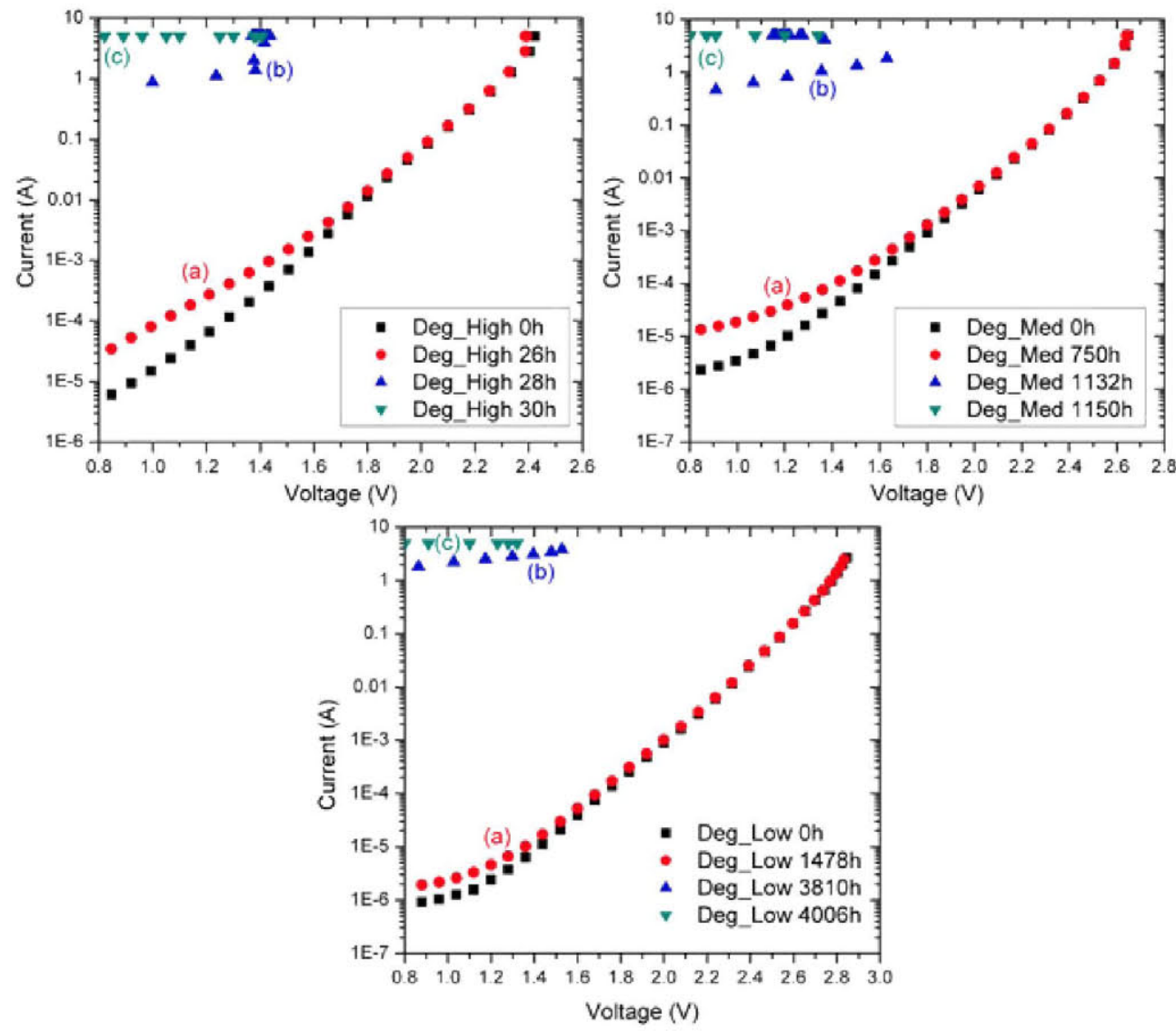

Figure 2. Typical dark I-V curve evolution of the solar cells with current injection during the ALT at the three climatic chamber temperatures (producing the following Tcell: Low $=119^{\circ} \mathrm{C}$; Med $=126^{\circ} \mathrm{C}$ and High $=164{ }^{\circ} \mathrm{C}$. See Table I). I-V curves evolve from the $0-h$ curve to curves (a), which show a decreased shunt resistance; followed by a remarkable voltage reduction, (b) and finally, they move to a complete short-circuit like performance (c). The erratic points on curves (b) and (c) are caused by the current limit setting of the power supply (see Figure 1), which was set to $5 \mathrm{~A}$ to avoid an accidental damaging of the solar cells.

carried out on cells before starting the ALT (section 3.1) is presented.

\subsection{Condition of solar cells before Alt}

The characterization of solar cells before ALT showed efficiencies of $37.5 \%$ around $820 \times$. Figures $3 \mathrm{a}-\mathrm{c}$ gather the typical EQE curves for top, middle and bottom cell, respectively. EL images can be seen in Figure 3d (top subcell) and $3 \mathrm{e}$ (middle subcell). The bottom cell is not shown because the Ge has indirect gap and our EL setup is not able to detect its weak EL. Additionally, we have used X-ray transmission imaging in order to have some information of the back contact of the solar cells tested. Both the EQE (Figure 3a c) and the EL (Figure 3d-e) measurements do not show neither anomalous behavior in the semiconductor structure nor in the metallization, implying that the three junctions are working properly and that current is homogenously distributed. Besides, the X-ray transmission images (Figure 3f) do not reveal the presence neither of voids nor of cracks in the back contacts. However, because this technique is not able to detect all kind of these defects we cannot totally dismiss their presence [3].

A chemical and optical analysis of the solar cell surface, busbar and front metal fingers was performed. Figure 4 shows a SEM planar view of the cell surface, where the composition of active area, fingers and busbars is identified using EDX. As can be seen, composition at the surface of the active area is $\mathrm{Al}-\mathrm{Ga}-\mathrm{In}-\mathrm{P}$, suggesting an $\mathrm{Al}(\mathrm{Ga}) \mathrm{InP}$ window on a GaInP top cell. The antireflective coating (ARC) which covers the active area, the fingers and partially the bus bar surface, is probably made up of $\mathrm{TiO}_{\mathrm{x}} / \mathrm{AlO}_{\mathrm{x}}$.

Fingers and busbars share the metallization elements, $\mathrm{Ag}$ and $\mathrm{Au}$. Ge is detected in both, the active cell surface and the metallization area. In the case of the active cell surface, the Ge presence could be justified because of Ge auto-doping coming from the $\mathrm{Ge}$ substrate evaporation during the MOVPE process [9] or also because of the Ge bottom cell signal. On the other hand, the Ge detection in the metallization area is remarkable because there are several microns of $\mathrm{Ag}$ and $\mathrm{Au}$ that could soften the Ge signal coming from the bottom cell (note that In, P signals 


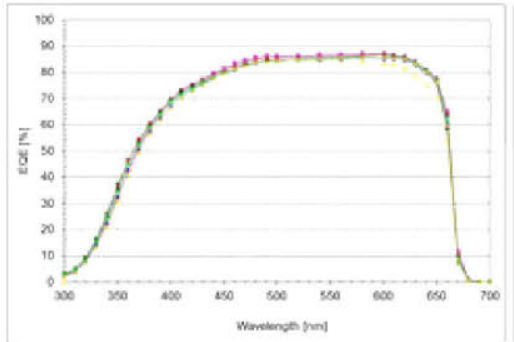

(a)

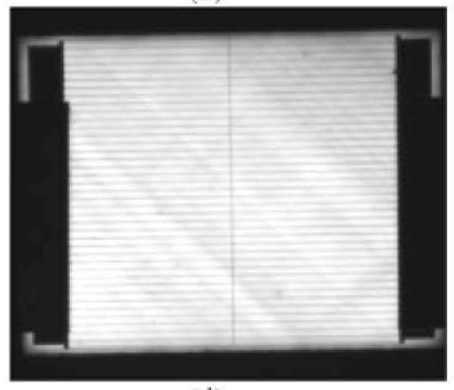

(d)

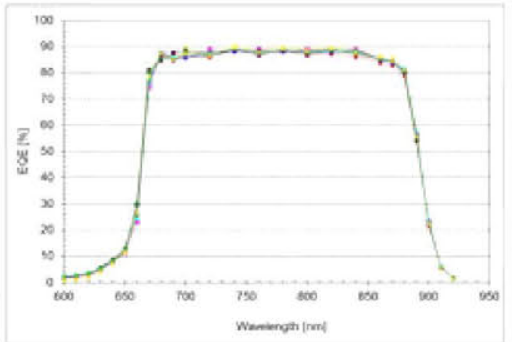

(b)

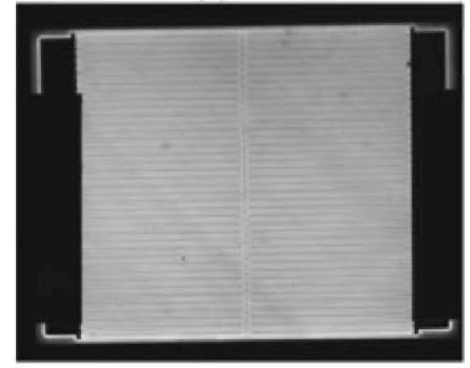

(e)

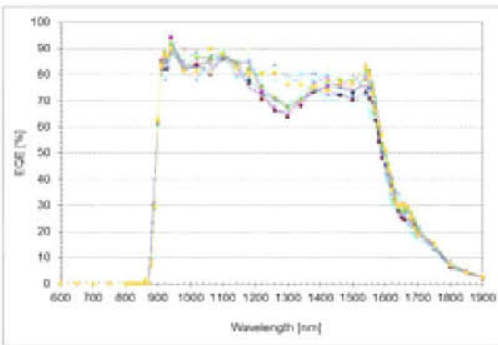

(c)

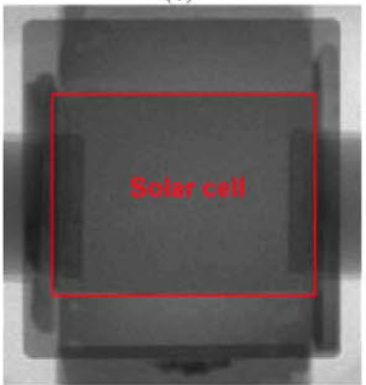

(f)

Figure 3. EQE of top (a), middle (b) and bottom cell (c) of several representative triple junction solar cells used in the ALT. EL at $1 \mathrm{~A}$ injection current of the top cell (d) and middle cell (e) of a representative triple junction solar cell. (f) X-ray image of a CoC (see Figure 1 right for a guide to the eye).

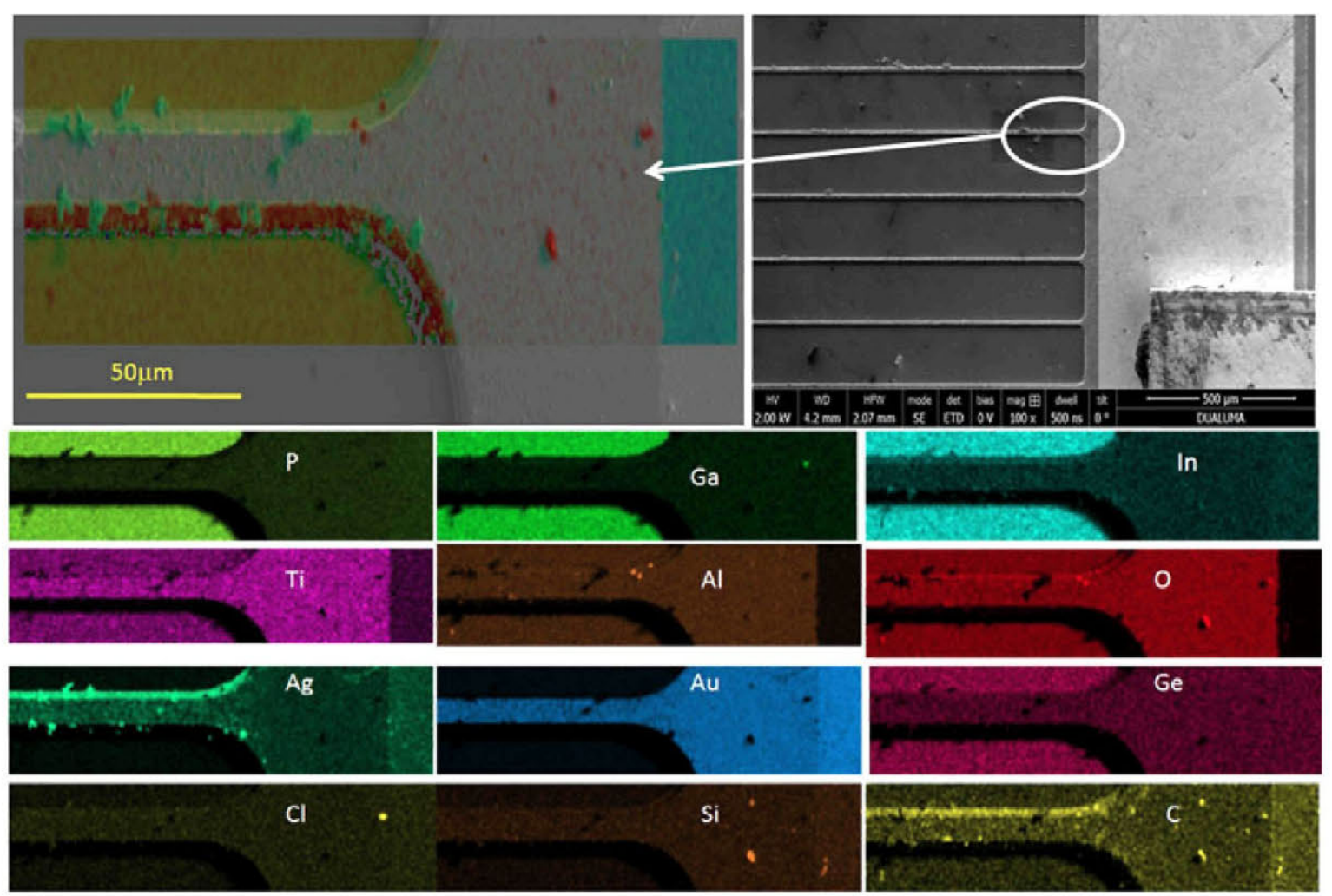

Figure 4. EDX mapping analysis of the cell surface, including active area, a finger and a busbar. The region of the solar cell analyzed is shown in the top right picture. 
from window layer are very weak in the area covered by the metallization bus and finger). This fact would indicate that $\mathrm{Ge}$ is one of the metallization constituents.

Finally, the bottom pictures in Figure 4 show the presence of unexpected contaminants like $\mathrm{Cl}$ and $\mathrm{Si}$ small brilliant balls on top of the bus bar surface - together with the most usual $\mathrm{C}$, due mainly to air exposure. Some other EDX analysis (not shown), mainly close to the cell perimeter, confirms the $\mathrm{Si}$ presence, usually combined with $\mathrm{C}$, in small balls on the cell surface. This would indicate that the silicone used to the cell assembling on the carrier were the most probable origin for this contamination (see Figure 1 right).

Concerning the solder used to bond the tab onto the busbar, several EDX analyses made at different points show a $\mathrm{Sn}-\mathrm{Pb}$ alloy. The presence of $\mathrm{Cl}$ and $\mathrm{Si}$ as small spots on the busbar surface probably came from the solder bath for the dipping process (in fact, the solder came from solder-dipped copper ribbon).

After FIB milling, the metallization cross section was revealed. Figure 5 shows the busbar composition profile cross section in a region covered in surface by ARC. Several EDX point analyses have been carried out along the whole busbar thickness as well on top of the ARC. The metallization is based on metallic Ag, and there are two very thin Au films sandwiching the silver layer, as it is shown in the two magnified pictures on the right side of Figure 5. The presence of $\mathrm{Ge}$ is detected in most of the points where EDX analyses have been performed, although its higher intensities are recording in spectra 2, 5 and 6, suggesting a $\mathrm{Au}-\mathrm{Ge}$ alloy in the metal layer contacting the top cell and also a Au layer with a lower Ge content on top of the silver layer (spectra 11, 12, 13). A mapping analysis made to detect the ARC composition (not shown) indicates that the $\mathrm{Al}_{2} \mathrm{O}_{3}$ layer is deposited onto the $\mathrm{TiO}_{2}$ layer.

Some other mapping analyses have been done along finger sections. Metallization follows the same scheme as in the bus bars, an annealed $\mathrm{Au}-\mathrm{Ge}$ region on top of the cell surface, covered by 5-7 microns thick Ag layer which is finally covered by around 0.25 microns Au layer with a low Ge content. In some analysis, some non-uniform thickness cross sections have been revealed after FIB milling (Figure 6), where a void in $\mathrm{Ag}$ bulk can be observed. EDX analysis in these areas evidences the presence of $\mathrm{Si}$ and $\mathrm{S}$, trapped as unexpected contaminants inside the metallization. The existence of these metal voids together with the surface roughness (see Figure 5 top right) would be compatible with an electroplated silver layer.

\subsection{Influence of temperature in the degradation process}

Dark I-V curves and EQE measurements were carried out on Ref_Low, Ref_Mid and Ref_High solar cells (see Table I), i.e. on solar cells that were not forward biased inside the climatic chambers during the ALT. Figure 7 left shows the pre- $(0 \mathrm{~h})$ and post-degradation dark I-V curves

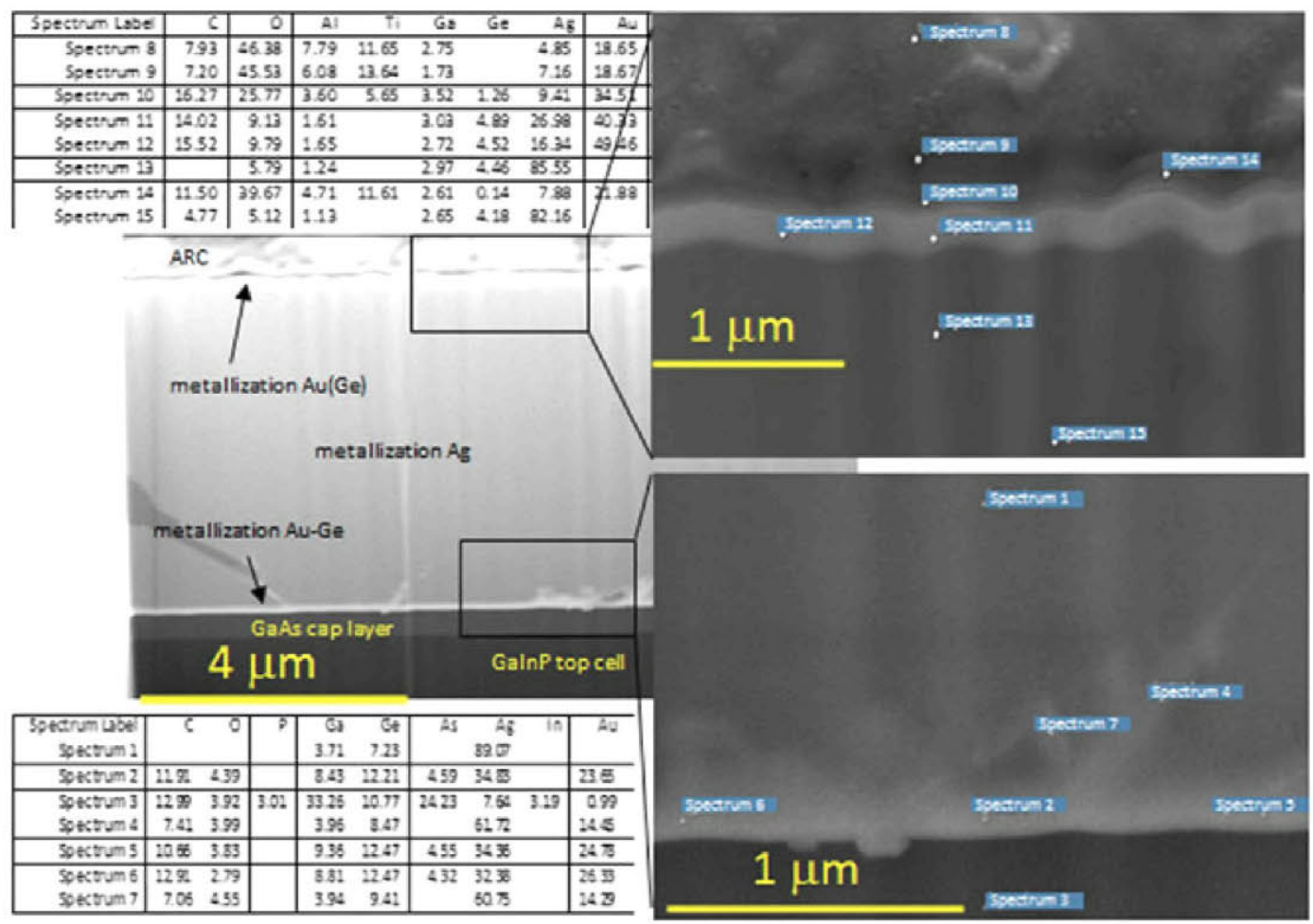

Figure 5. Left, cross-section SEM view of the busbar covered with ARC. Right, magnified pictures showing the Au films on top of and beneath the bulk Ag. Tables correspond to EDX points analysis. 


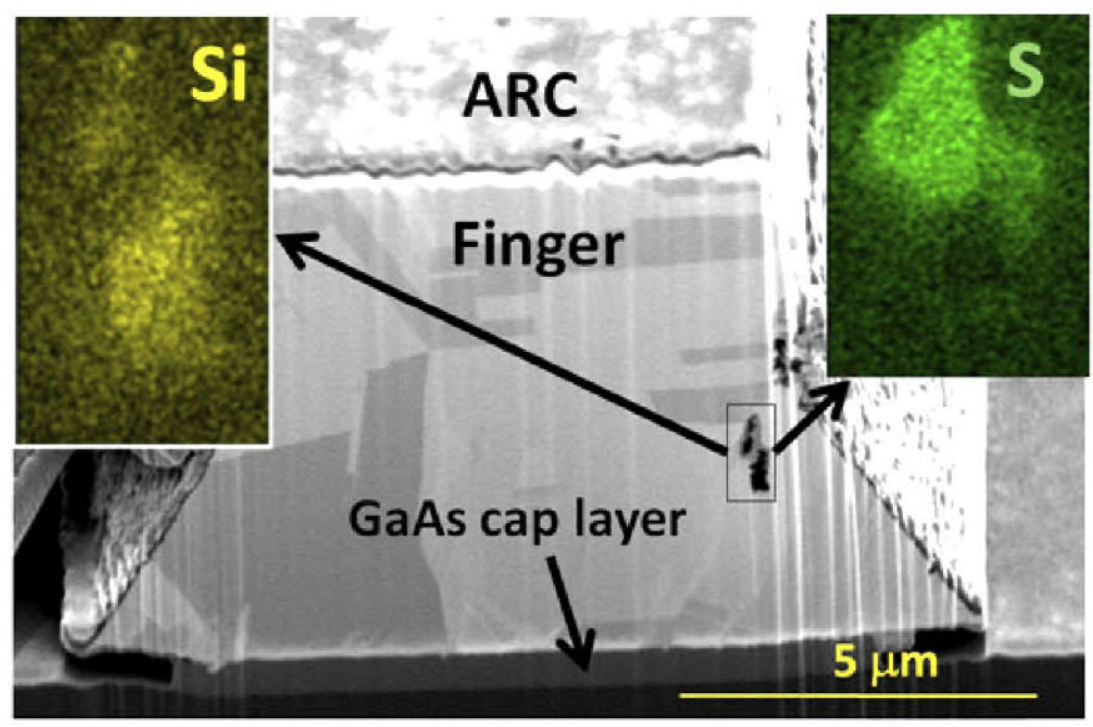

Figure 6. Cross-section SEM picture of a finger with the EDX analysis of the voids surrounded with the black rectangle.
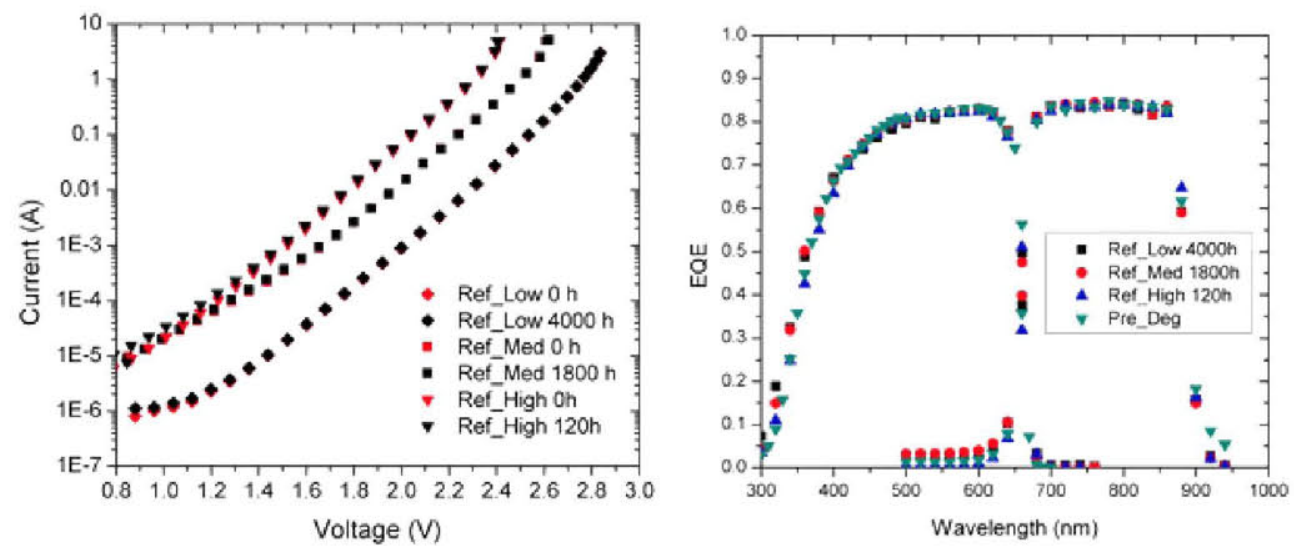

Figure 7. Dark I-V curves of reference solar cells (see Table I) before $(0 \mathrm{~h}$ ) and after the temperature degradation at the three climatic chambers. Measurements were performed at the Tcell stated in Table I for the corresponding reference cell (left). EQE at $25^{\circ} \mathrm{C}$ of the reference solar cells after the temperature degradation in comparison with their performance before the tests. Because of the negligible differences among the three cells before degradation, only one of their EQE is shown for simplicity "Pre_Deg" (right). EQE of Ge bottom subcell is not shown for simplicity.

of the three reference cells, while Figure 7 right shows the pre- and post-degradation EQEs of the Ref _Low, Ref_Mid and Ref_High solar cells. As can be seen, preand post-degradation dark I-V curves are virtually identical with only a very slight difference at very low voltages. Regarding $\mathrm{EQE}$, the differences are also negligible.

Despite there are no changes in the optoelectronic performance of reference solar cells before and after temperature stress (without current injection), their front cell surface and the front metal grid have been examined by SEM and EDX (not shown). Again, no significant differences have been found when comparing these measurements with those obtained before the ALT (see section 3.1).
The chemical composition along the semiconductor structure of the three reference solar cells (Ref_Low, Ref_Mid and Ref_High) has been measured by means of EDX in STEM mode. In Figure 8, the spectra for the GaInP top subcell, the AlGaAs top tunnel junction anode, the GaInP top tunnel junction cathode and the GaInAs ( $1 \%$ of In) middle subcell for the three devices are gathered. The constituent elements for the different layers are pointed out in the plot in order to compare the composition of the three solar cells-i.e Ga-L $\alpha 1$ (1.098 keV), As-L $\alpha 1$ (1.282 keV), Al-K $\alpha 1,(1.487 \mathrm{keV})$, $\mathrm{P}-\mathrm{K} \alpha 1(2.014 \mathrm{keV})$ and $\mathrm{In}-\mathrm{L} \alpha 1(3.288 \mathrm{keV})$. Figure 8 shows that the different layer spectra are virtually identical for the three reference solar cells. This result implies that there are no significant inter-diffusions of the constituent 


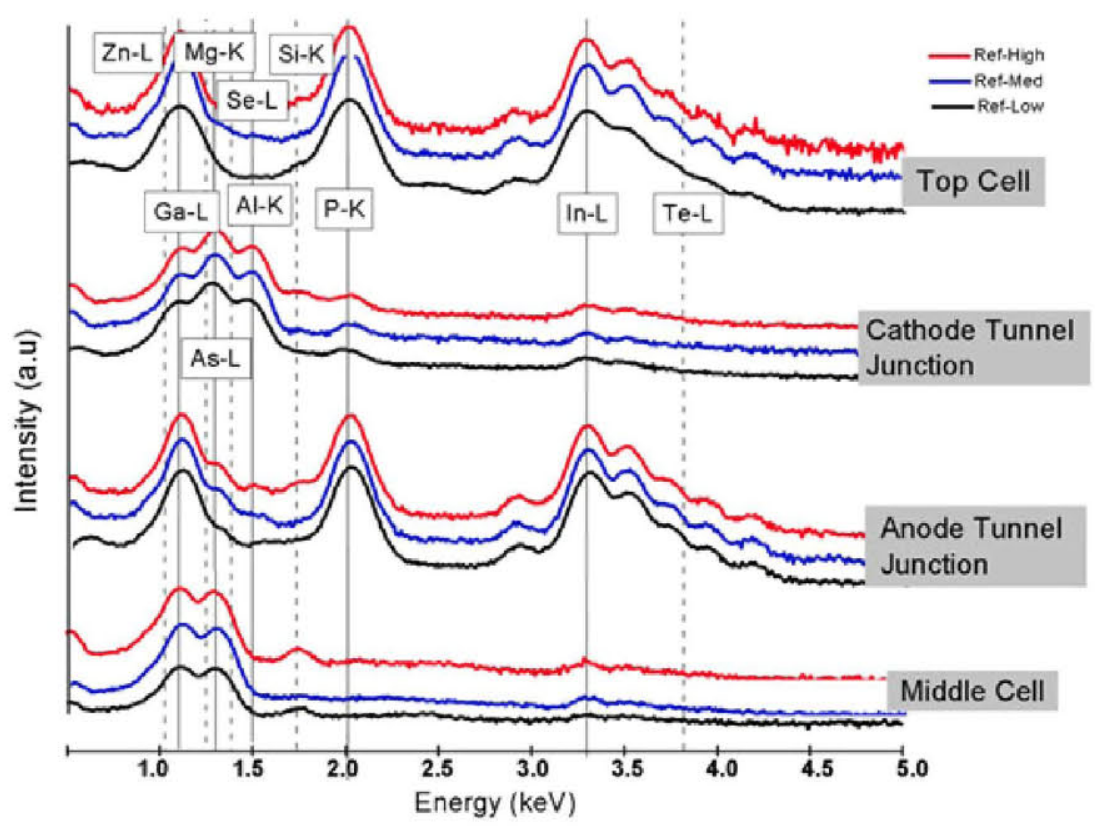

Figure 8. EDX spectra of the different semiconductor layers for three reference solar cells aged at different temperatures. The dopant $(\mathrm{Zn}, \mathrm{Mg}, \mathrm{Se}, \mathrm{Si}$ and $\mathrm{Te}$ ) energies are indicated by dashed lines for a clearly understanding of the different spectra peaks.

elements as a result of the devices temperature exposure. Regarding the most likely III-V dopants, Mg-K $\alpha 1$ $(1.253 \mathrm{keV})$ and $\mathrm{Zn}-\mathrm{L} \alpha 1(1.012 \mathrm{keV})$ for p-type and $\mathrm{Se}-\mathrm{L} \alpha 1(1.379 \mathrm{keV}), \mathrm{Si}-\mathrm{K} \alpha 1(1.740 \mathrm{keV})$ and $\mathrm{Te}-\mathrm{L} \alpha 1$ $(3.770 \mathrm{keV})$ for n-type are indicated in Figure 8. The $\mathrm{X}$-ray signals for $\mathrm{Zn}-\mathrm{L} \alpha 1 \quad(1.012 \mathrm{keV}), \quad \mathrm{Mg}-\mathrm{K} \alpha 1$ $(1.253 \mathrm{keV})$ and Se-L $\alpha 1(1.379 \mathrm{keV})$ are all of them located in the energy range dominated by Ga-L $\alpha 1$, As- $\mathrm{L} \alpha 1$ and $\mathrm{Al}-\mathrm{L} \alpha 1$ peaks, while $\mathrm{Te}-\mathrm{L} \alpha 1(3.770 \mathrm{keV})$ locates in the In peaks, making impossible their precise detection by means of EDX. Anyhow, no noticeable variations around these peaks are perceived in Figure 8.

In summary, we can conclude that the solar cells that were only exposed to high temperature showed no degradation, neither in the semiconductor structure, nor in the metallization. Therefore, the initial degradation and, later on, the catastrophic failures presented in Figure 2 must be caused by a combination of bias current and temperature. This is analyzed in section 3.3.

\subsection{Combined influence of temperature and current injection in the degradation process}

Section 3.2 shows that solar cells present no degradation if they are stressed only by means of the high temperatures used in the ALT. However, Figure 2 shows that when solar cells are forward biased, they presented the same evolution toward failure, although the elapsed time depends on the chamber temperature. Therefore, it can be concluded that under forward bias the effect of temperature was accelerating the rate at which each solar cell failed. This corresponds with the statistical reliability analysis obtained in [5] where the higher the temperature, the higher the acceleration factor of the ALT. When forward biasing together with high temperature is used, the degradation observed has two stages, namely the degradation of the front contact and the appearance of cracks in the semiconductor structure.

\subsubsection{Degradation of the front contact.}

Optical microscope analysis reveals degradation of the current injection busbar and nearby fingers and even some cracks in the semiconductor surface. Figure 9 shows an example for the three tested temperatures.

XPS analysis can shed some light onto the chemical evolution of the busbar surface composition after the ALT. Figure 10 gathers the spectra collected on both busbars of the same cell, namely on the busbar where current is injected (green line Figure $10 \mathrm{a}$ ) and on the busbar where voltage is measured but without current injection (blue line Figure 10 a) according to the schematics shown on Figure 1. Traces of several contaminants such as Al, Si, $\mathrm{S}$ and $\mathrm{Cl}$, have appeared in the XPS survey spectra of non-injection busbars (Figure $10 \mathrm{a}$, top blue line). Si presence was also detected by EDX surface analysis, and it could be because of residues of the cell assembling onto its carrier. Silicon appears in both injection and noninjection busbars. Sulfur could be a silver electroplating process debris [10] because Ag3d [11] and S2p (not shown) core level deconvolution demonstrates the presence of a very small quantity of silver sulfide on top of the no current injection busbar surface. $\mathrm{Al}$ and $\mathrm{Cl}$ do not have a clear origin. They might be impurities of the solder bath for the dipping process. $\mathrm{Cl}$ was also detected in the EDX surface analysis of cells before starting ALT (see section 3.1). Al presence may be also because of the 

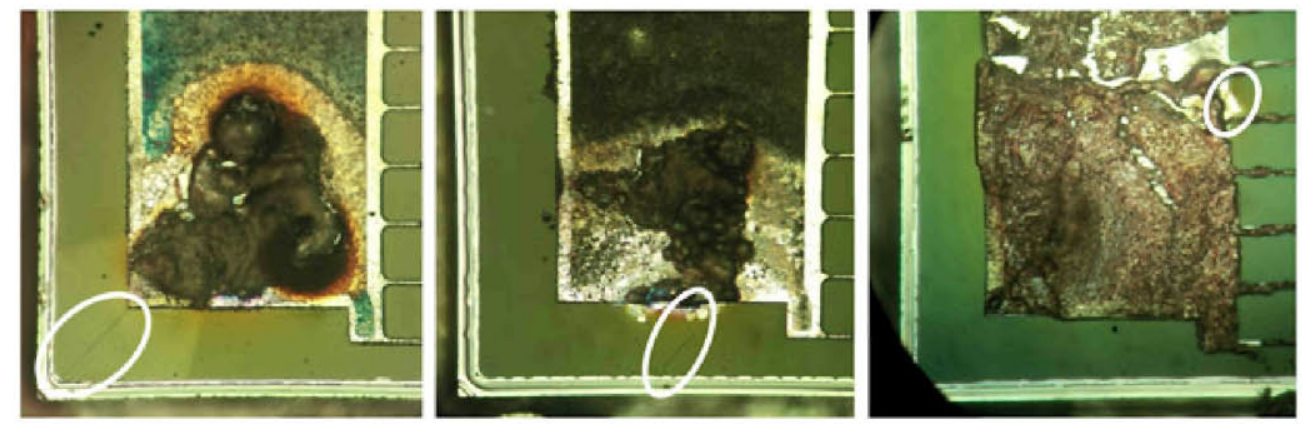

Figure 9. Injection busbar evolution of solar cells tested at $119^{\circ} \mathrm{C}$ (left), $126^{\circ} \mathrm{C}$ (center) and $164^{\circ} \mathrm{C}$ (right). Some cracks on the semiconductor surface are also visible (highlighted with white ellipses).

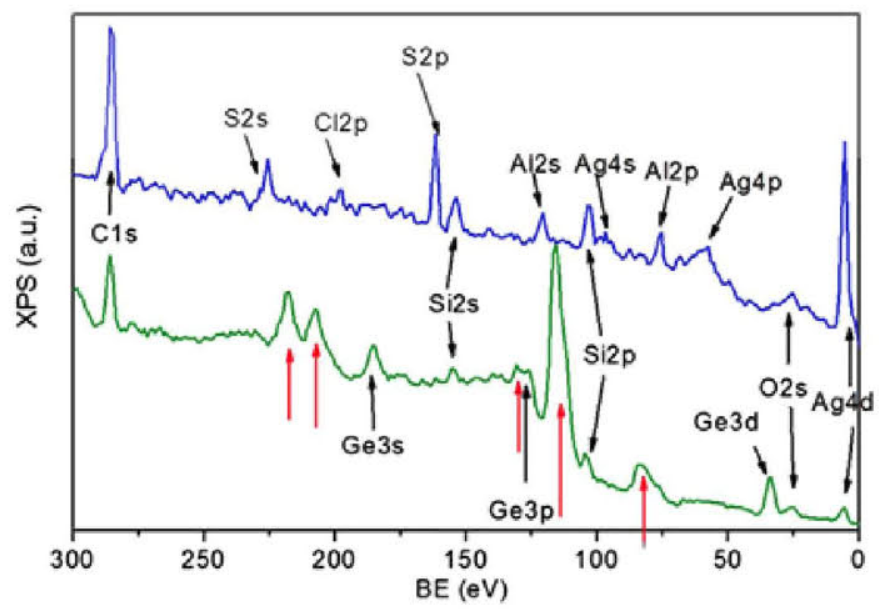

(a)

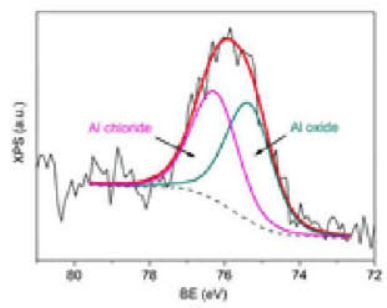

(b)

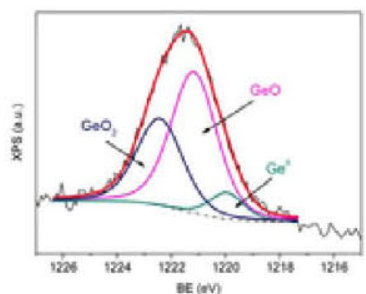

(c)

Figure 10. (a) Survey spectra corresponding to a no current injection (top, blue line) and current injection (bottom, green line) busbars. The core level elements are identified in the graphics. Red arrows mark the GeLMM Auger transition feature visible in the injection bus. (b): Al $2 p$ core level deconvolution for a no current injection busbar; (c) Ge2p3/2 core level deconvolution for a current injection busbar. Signal constituents are identified in the graphics.

cell surface ARC $\left(\mathrm{AlO}_{\mathrm{x}}\right)$. Besides, Al2p core level peak has two contributions (Figure 10, right top), namely the lower energy one corresponds to Al-oxide while the other one has a binding energy which is compatible with Alhalides, being $\mathrm{Al}$ chloride (which could be derived from a silver halide which is a typical constituent of the electrolyte of the electroplating process) the most probable one.

In the current injection busbar, most of these contaminants are absent or their presence could not be detected because of an unexpectedly high quantity of Ge on the busbar surface (Figure 10 left, lower line). A lowering Ag core level intensity and a noticeable increase of O1s signal accompany the Ge emergence. Moreover, Ag chemical state evolves because of current injection, and most of the silver is now oxidized [11]. Ge2 $p_{3 / 2}$ core level evidences that most of the Ge is also in an oxidized state (Figure $10 \mathrm{c}$ ). The degradation of the $\mathrm{Ag}$ busbar has been also identified in $\mathrm{GaInP} / \mathrm{GaInAs} / \mathrm{Ge}$ triple junction space solar cells as the failure origin although the aging conditions were different than those of this paper [12].
SEM images also prove the deterioration that the ALT causes on the front metal contact. In Figure 11, a planar view image shows a very irregular surface corresponding to a busbar with current injection and not covered by ARC. A mapping EDX analysis has been performed in the area surrounded by the yellow rectangle. A very irregular distribution of silver and gold is the first conclusion extracted from these images. The Au layer is not continuous anymore. Besides, the presence of $\mathrm{S}$ and $\mathrm{Cl}$ is evident as well as that of $\mathrm{Pb}$ and $\mathrm{Sn}$, which are the soldering components. The presence of these four elements supports the busbar surface chemical evolution pointed in the XPS measurements. In particular, $\mathrm{S}$ and $\mathrm{Cl}$ show a high chemical reactivity, and this fact could be an accelerating factor in the busbar deterioration during ALT. In some other analysis, $\mathrm{Al}$ is also detected. It is worth mentioning here that the analyzed area was not under the contact tab. The equivalent analysis made on the no current injection busbar (not shown) produces partially different results because the $\mathrm{Au}$ and $\mathrm{Ag}$ keep a rather uniform distribution 


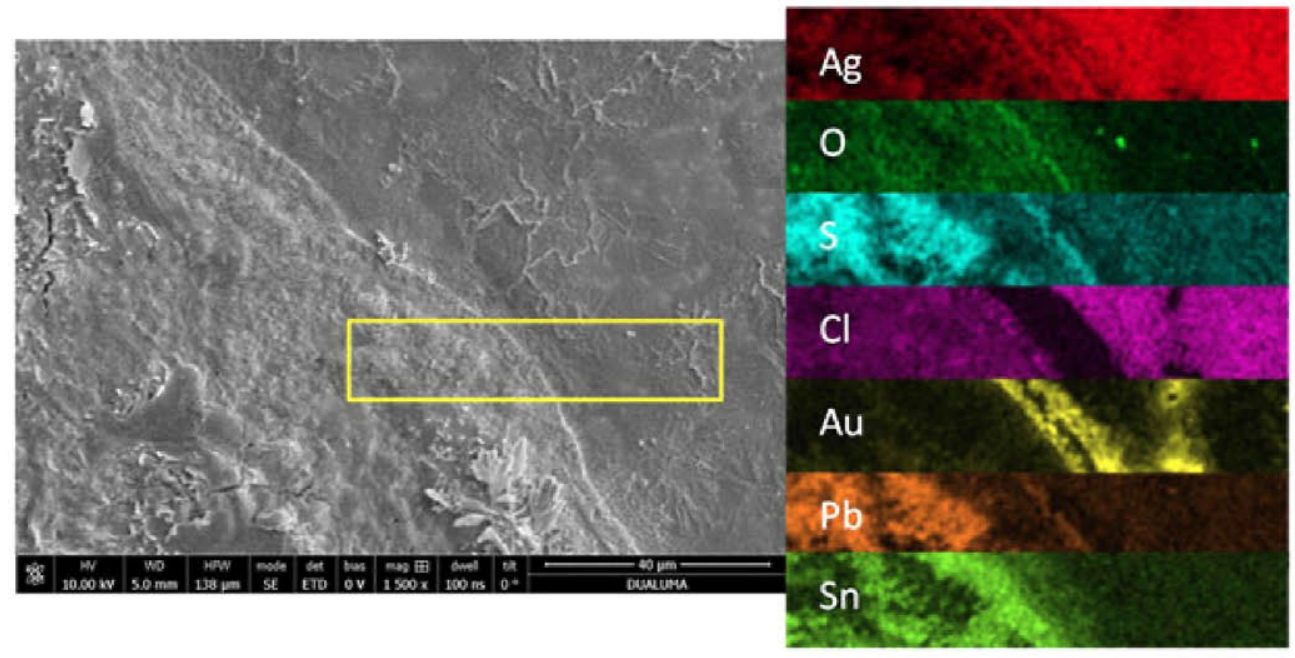

Figure 11. Left, planar view of a busbar with current injection, showing an irregular busbar surface. Right, mapping EDX analysis with the resulting detected elements.

together with the presence of $\mathrm{Cl}, \mathrm{Al}$ and $\mathrm{S}$. On the contrary, $\mathrm{Pb}$ and $\mathrm{Sn}$ were not detected in the busbar areas not covered by the contact tab.

The busbar area beneath the tab exhibits also a deteriorated aspect. A cross-section SEM picture confirms the lack of uniformity of the Au top layer. In Figure 12, several EDX analyses have been performed in the marked points. It is remarkable the appearance of $\mathrm{Sn}$ well below the busbar surface suggesting a mixture among the metallization and solder elements.

\subsubsection{Appearance of cracks on the semiconductor structure.}

The fact that the metallization is so damaged undoubtedly has consequences on the electrical current flowing across the busbar thickness. Because of its non-

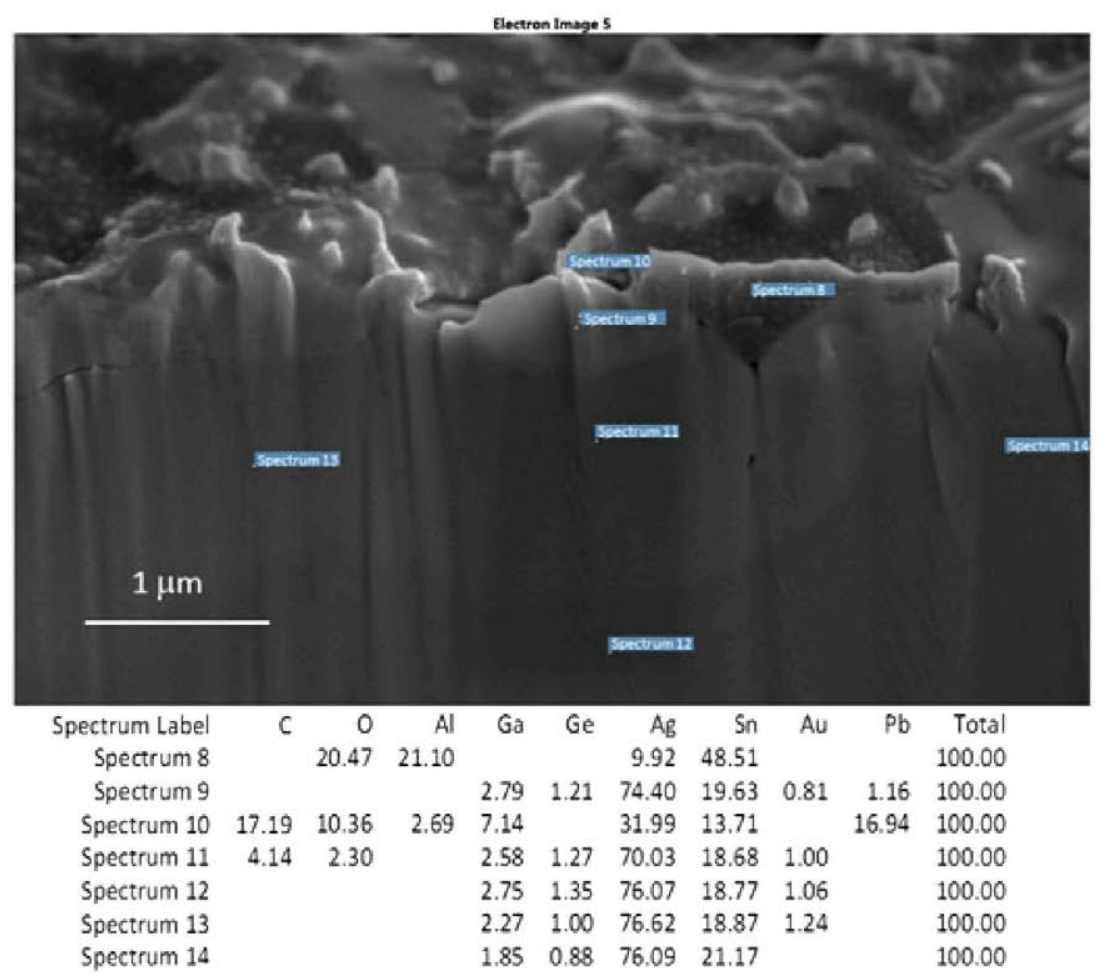

Figure 12. Cross-section SEM picture of the current injection busbar beneath the tab, corresponding to the "Deg_Mid" solar cell. 
homogeneous composition, the busbar has a nonhomogeneous metal sheet resistance. Therefore, busbar is not equipotential at all, and current cannot flow uniformly through the whole busbar volume. This means that the current density can be much higher in some regions thus creating hot spots. In addition, these hot spots could induce mechanical stress either between the evaporated $\mathrm{Au}-\mathrm{Ge}$ layer and the electroplated silver resulting in the busbar liftoff or to promote cracks in the surrounding semiconductor. No changes have been observed in the evaporated $\mathrm{Au}-\mathrm{Ge}$ layer so no degradation of the contact resistance is expected.

Cross-section images of the injection busbars evidence how mechanical stress affects the metallization. In several cell surface areas, the electroplated metal has raised up, leaving just the evaporated metal layer (Figure 13 (a)). Cross-section images after FIB milling were taken in order to show how this busbar is completely separated from the cell surface (Figure 13 (b)). In some cases, the busbar deterioration has also induced the apparition of cracks in the active surface cell (Figure 13 (c)). Figure 13 (d) illustrates the propagation of a crack along the semiconductor structure. Except for these cracks, no damage of the semiconductor structure has been observed in the cross-section SEM images. Also, we have seen in [1] that electroplated silver lift-off forces the circulation of very high current densities into the semiconductor in very small areas of the cell structure. The confinement of these high current densities into small semiconductor regions would have favored the creation of defects and cracks turning the solar cells into shunts.

\subsubsection{Solar cell failure: localized shunts.}

As we have stated in Section 2, dark I-V curves, EL and $\mathrm{EQE}$ measurements of the degraded solar cells show very low shunt resistances, behaving as virtual short circuits. Therefore, solar cells at their final degradation stage (curves (c) of Figure 2) did not exhibit any answer to $\mathrm{EQE}$, illumination $\mathrm{I}-\mathrm{V}$ curve and EL measurements. Consequently, in order to shed some light on the solar cell performance just before failure, we stopped the ALT when some solar cells, namely "Deg_Low S (I)", "Deg Low S (II)" and "Deg_Mid_OK" (see Table I), had not yet became short-circuits (i.e. they did not reach yet stage (c) of Figure 2) although they exhibited an intense degradation. This allowed us to measure their EQE, illumination I-V curve and EL in order to know their performance as solar cells before their catastrophic failure. The results are presented below. Besides, these solar cells were also characterized by SEM, EDX, etc. showing the same results that

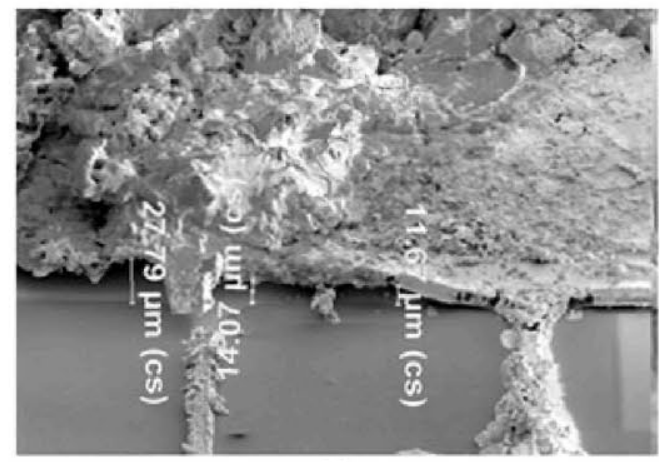

(a)

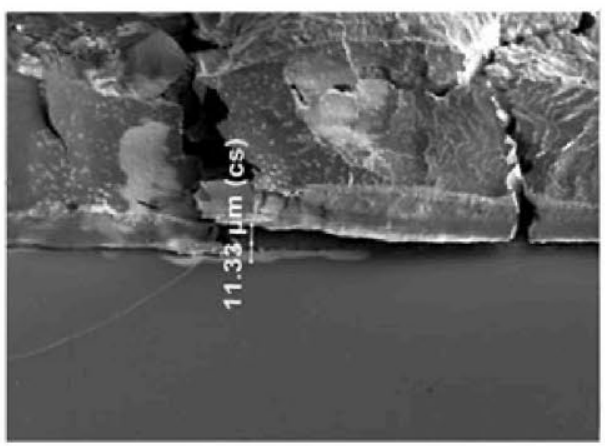

(c)

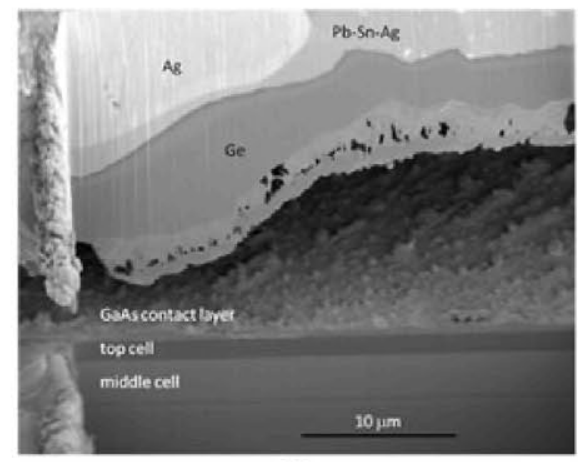

(b)

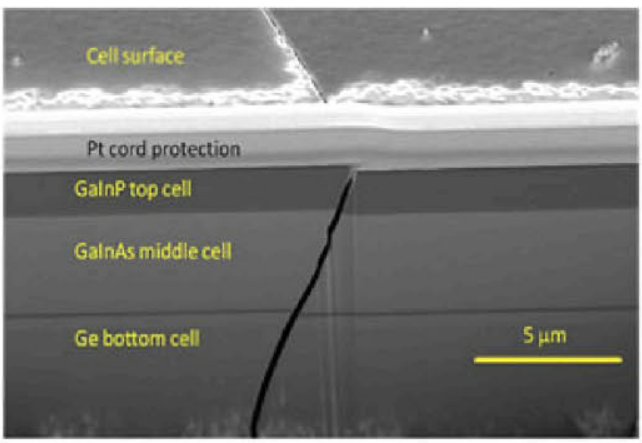

(d)

Figure 13. SEM images of an injection busbar in cells aged at $126^{\circ} \mathrm{C}$ (a) and $164^{\circ} \mathrm{C}$ (b). Picture of the left is a tilted front surface image. The image on the right is a cross section taken after FIB milling showing the separation between the metallization and the cell surface. SEM image of the lifted bus and a crack induced in the active surface cell by the metallization mechanical deterioration (c). The crack propagates along the whole semiconductor structure thickness (d). White brilliant cord is the Pt protection to avoid FIB mill-

ing damage on the cell surface. 
the completely degraded (shunted) cells described in sections 3.3.1 and 3.3.2. In a nutshell, solar cells "Deg_Low S (I)", "Deg Low S (II)" and "Deg_Mid_OK" had the same structural and chemical degradation footprint than the completely shunted cells with the only difference that they have not reached the total failure stage (namely, c stage in Figure 2), so they still exhibited some solar cell response.

First, we have intensively looked with SEM for the appearance of metal spikes as responsible for the short circuit but we have not found them [11]. Therefore, we have discarded the short circuit by metal diffusion and looked for alternative origins for the electric short.

Figure 14 shows the top cell EL of solar cell (Deg_mid_OK) which does not present an homogenous emission distribution, contrarily as it was observed for the reference cells in section 3.1 (Figure 3). Regions near the defects close to the busbars corresponding to cracks similar to those shown in Figures 9 and 13, are brighter, implying that most of the bias current is drained through them, thus helping to pinpoint the location of the shunts in the top cell. A similar finding was presented in [3].

We think that this type of localized shunts is extended until the top subcell is totally shunted. This was observed on the "Deg_Low_S (II)" solar cell (see Table I) that had no top subcell EQE response but still had a decent middle subcell EQE (see Figure 15, right). Figure 15 left shows a greatly overexposed EL image of the middle subcell of this solar cell where it is clear that most of the current comes from the top subcell through a shunt close to the busbar and then current distributes laterally through the middle subcell including a perimeter region out of the busbar.

The final observable stage in the degradation process would be the total shunting of the middle subcell. This would explain the observed performance evolution for all the degraded solar cells which were not disconnected from the current source before reaching the stage (b) of Figure 2 (this happened with all the cells with current injection excepting the aforementioned "Deg_Low_S" solar cells). Because those solar cells have very low shunt resistances on the middle and top subcells, it is impossible to measure the bottom subcell EQE although it would be still in operation [13].

SPICE simulations were carried out to model the degradation stages proposed in this section (see Figure 16). The values for sheet resistances (R_TC1, R_MC1, R_BC1), metal grid resistance ( $\mathrm{R}$ grid), degraded side shunt resistances (Rp_TC_Sh1, Rp_MC_Sh1, Rp_BC_Sh1), nondegraded side shunt resistances (Rp_TC1, Rp_MC1,

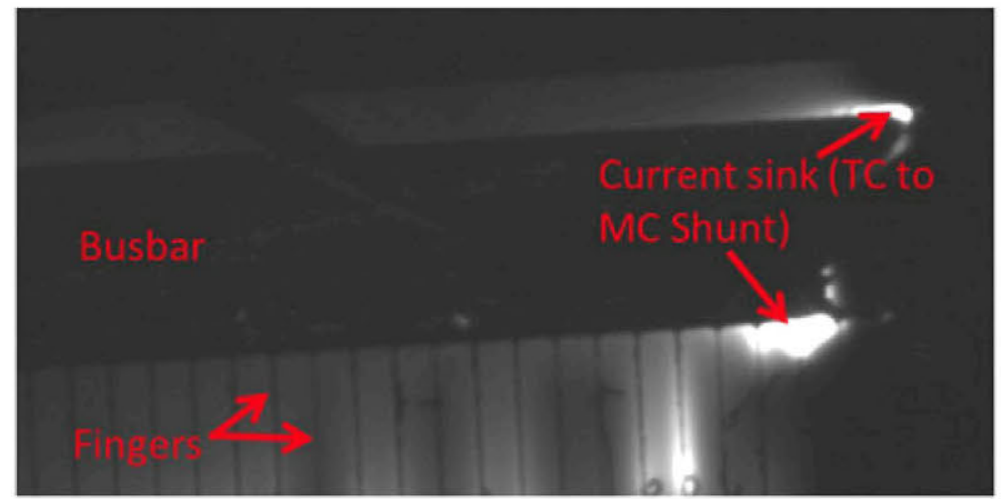

Figure 14. EL image of the top subcell of solar cell Deg_Mid_OK showing the shunts performing as current sinks near the busbar.
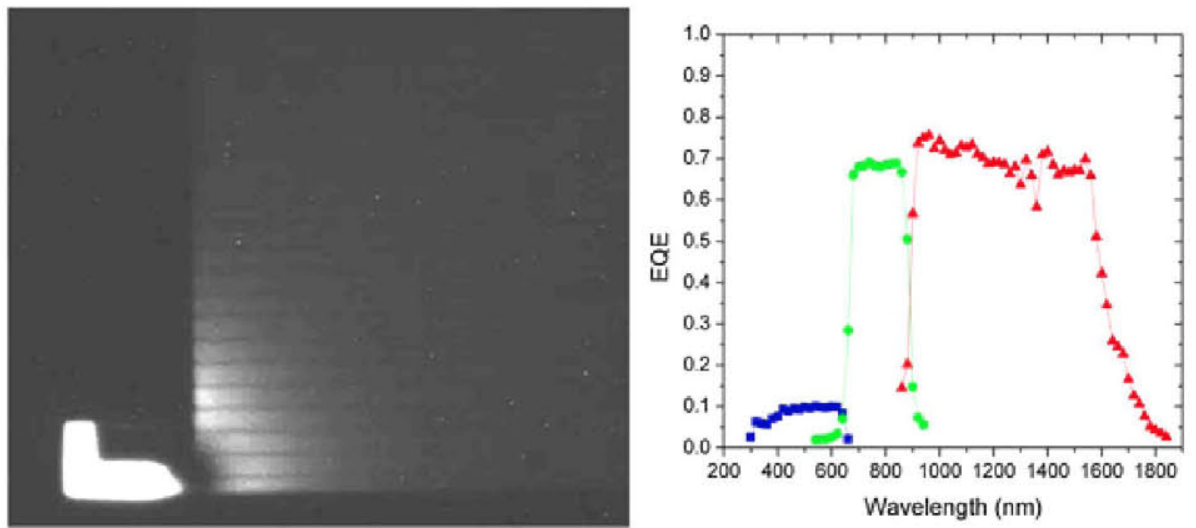

Figure 15. Left: EL image of the middle subcell of the "Deg_Low_S (II)" solar cell and its corresponding EQE (right). 


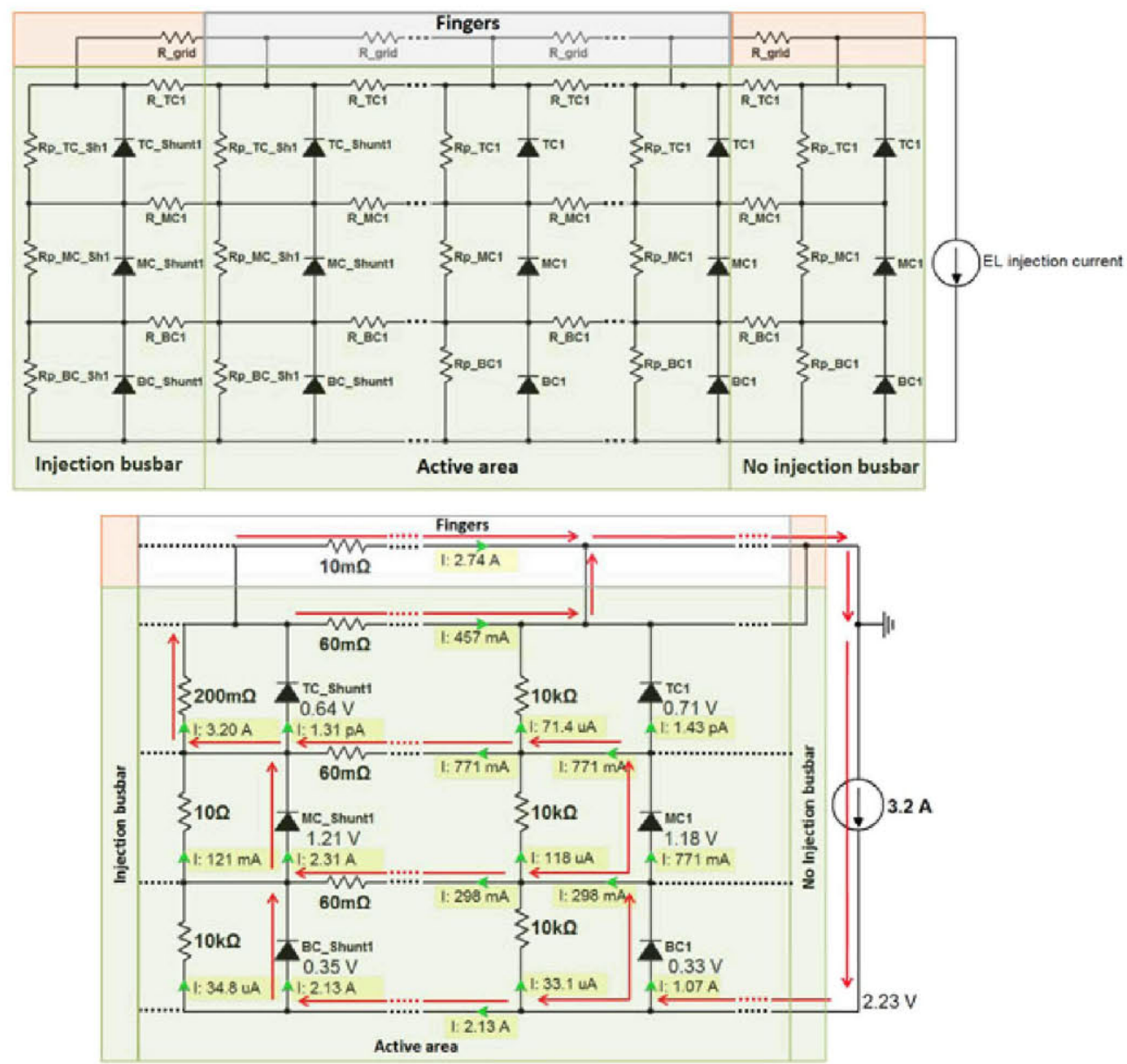

Figure 16. Top: SPICE circuit used to model the behavior of the degraded solar cells when EL measurement is in damaged cells is performed such in Figure 15 Bottom: SPICE circuit that simulates EL biasing when there is a shunted part of the top cell with some damage in the middle subcell. The red arrows represent the main path followed by the current flow injected into the solar cell. This implies that the current densities in the middle and bottom subcells near the top subcell shunt are huge, leading to the failure of the middle subcell shortly after the appearance of the top subcell shunt (as it is proposed above). On both figures, the dotted lines mean that the circuits representing the non-degraded parts of the solar cell are repeated multiple times to create the complete solar cell.

Rp_BC1) and the parameters for each diode (TC1, MC1, BC1, TC_Shunt1, MC_Shunt1, BC_Shunt1) were obtained from $\mathrm{I}-\mathrm{V}$ curve measurements on both degraded and non-degraded solar cells, and from four point probe resistivity measurements, in combination with the use of our triple junction solar cell 3D modeling [5].

By properly changing the values of Rp_TC_Sh1 and Rp_MC_Sh1, it is possible to replicate the aforementioned stages (top cell and middle subcell EL, top cell low EQE with a decent middle cell EQE, etc.) of the degraded solar cells, giving confirmation that the failures are caused by the subsequent shunting of the subcells. As an example, Figure 16 bottom emulates the situation shown in Figure 15 where there is no top cell EL while some middle cell EL is detected. The main current paths are represented with red arrows while green arrowheads show the current value for each path. The values selected for Rp_TC_Sh1 $(200 \mathrm{~m} \Omega)$ and Rp_MC_Sh1 $(10 \Omega)$ represent the case where the top subcell is completely shunted while the middle subcell exhibits some damage. The middle subcell diode (MC_Shunt1) is biased at $1.21 \mathrm{~V}$, allowing the EL emission in spite there is some damage to this subcell (GaAs diode). On the contrary, the top subcell diode (TC_Shunt1) is biased at $0.64 \mathrm{~V}$ preventing any EL emission (GaInP diode). Notice that all the current coming from the external generator flows through the damaged part of the top subcell, creating a hotspot which will cause the thermal runaway observed in this ALT and in the previously mentioned works $[2,3]$.

In spite of the aforementioned proofs, it can be argued that the EQE degradation can be deemed in terms of the effect of shunts together with the worsening of the semiconductor material properties. In order to address this last aspect, the shunted region of a degraded solar cell (Deg_Mid) was isolated. This was carried out by cutting this region with a diamond tool. This solar cell did not 

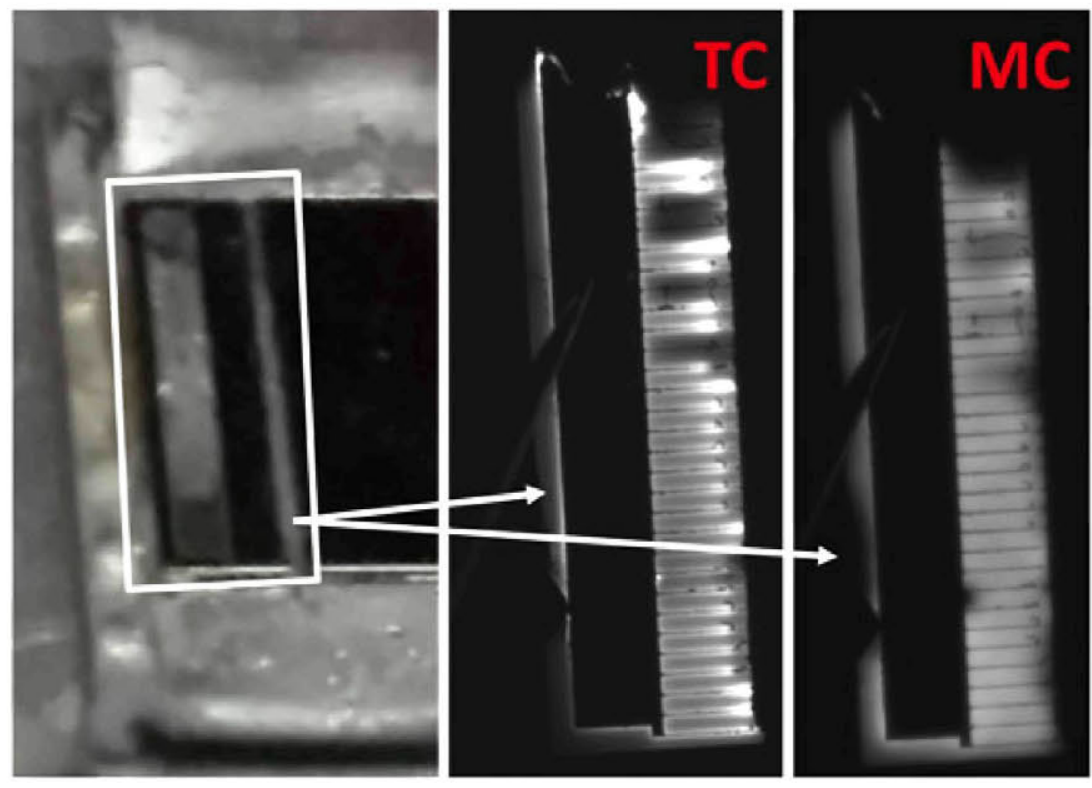

Figure 17. Left: Image of the cut applied on the shunted "Deg_Mid" solar cell. Center: Magnification of the top subcell EL image. Right: Magnification of the middle subcell EL image.

show any EL response before the cut while it recovered the EL response after the cut (see Figure 17). This fact is a demonstration that once the semiconductor shunts are suppressed, the solar cell performance is restored. Therefore, a damage of the semiconductor structure - in terms of intrinsic performance-seems unlikely.

In order to confirm that a semiconductor intrinsic failure can be definitively discarded, a detailed inspection of the semiconductor structure was carried out. Figure 18 gathers the EDX spectra in STEM mode for the GaInP top subcell, top tunnel junction (AlGaAs/GaInP) and the $\mathrm{Ga}(\mathrm{In}) \mathrm{As}$ middle subcell for the "Deg_Mid" cell beneath both no injection and injection busbars and also for the "Ref_Med" cell. The data are analyzed using the same criteria followed for the reference solar cells (Figure 8). As can be seen in Figure 18, there are not significant element interdiffusions

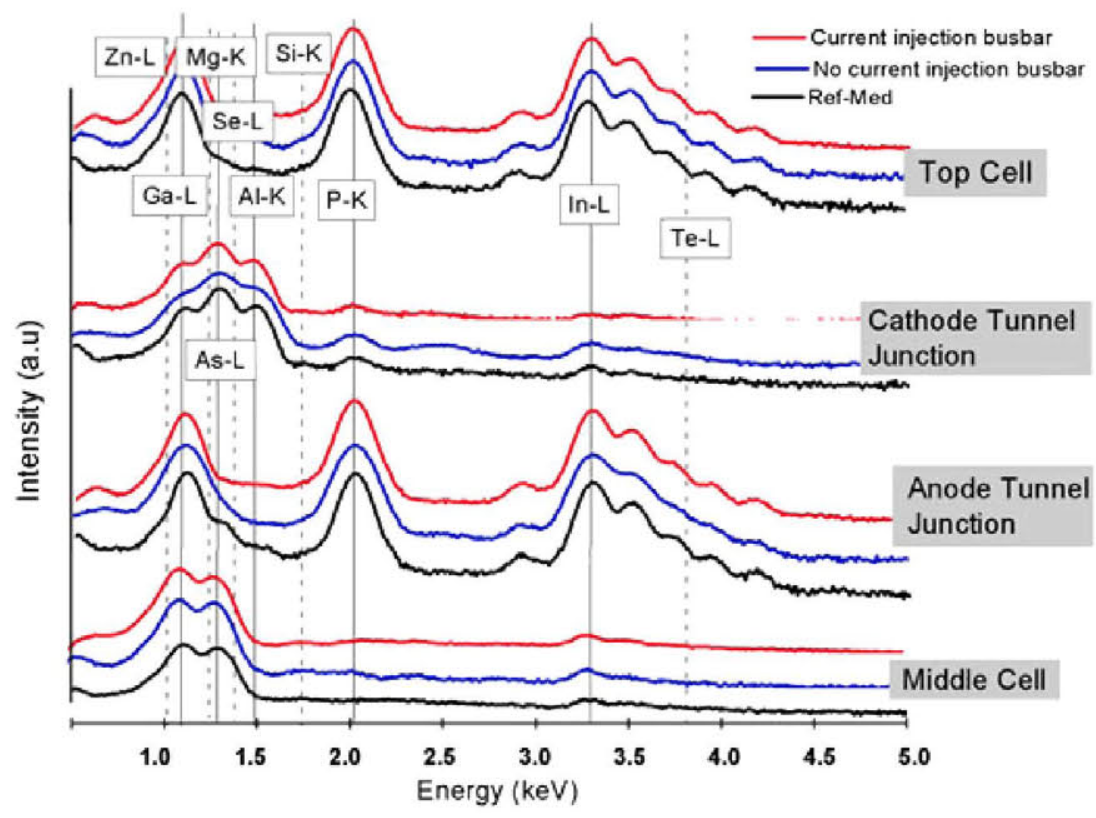

Figure 18. EDX spectra of the different semiconductor layers for a "Deg_Mid" cell in the region under the no current injection busbar and the region under the current injection busbar. The spectra for the Ref_Med solar cell have been included for comparison. The dopant $(\mathrm{Zn}, \mathrm{Mg}, \mathrm{Se}, \mathrm{Si}$ and $\mathrm{Te})$ energies are indicated by dashed lines for a clearly understanding of the different spectra peaks. 
when temperature together with current are applied. Because this also happened in Figure 8 when only temperature was the stress factor, we can conclude that current injection, even for the high current densities achieved in some regions beneath the injection busbar after its degradation, does not provoke the deterioration of the semiconductor structure. This analysis has also been carried out doing compositional profiles across the semiconductor layers, achieving the same conclusion: there are not significant cross-diffusions through the solar cell structure.

\section{SUMMARY AND CONCLUSIONS}

Failure analysis has been carried out after a temperature ALT on lattice matched $\mathrm{GaInP} / \mathrm{Ga}(\mathrm{In}) \mathrm{As} / \mathrm{Ge}$ triple junction commercial solar cells. Solar cells were forward biased in darkness inside three climatic chambers in order to emulate the photo-generated current under nominal working conditions (a concentration level of 820 suns).

Some cells (called reference cells) were not forwarded biased and just experienced a temperature stress. These solar cells impacted by temperatures as high as $164{ }^{\circ} \mathrm{C}$ do not degrade their performance, and a detailed analysis of both the front metal contacts and semiconductor structure by SEM, EDX and STEM does not show any kind of degradation either. On the other hand, the cells experiencing the combined temperature and current injection stress result in a severe degradation conducting to a short-circuit-like failure.

Current is identified as the cause of degradation while temperature just dominates the accelerating factor of the ALT. Current promotes the front metal damage produced by the chemical evolution of the electroplating impurities $(\mathrm{S}, \mathrm{Cl})$ together with those of the tab soldering process $(\mathrm{Pb}, \mathrm{Sn})$. This metallization damage has consequences on the electrical current flowing across the busbar thickness. Because of its non-homogeneous composition, the busbar is not equipotential at all and current cannot flow uniformly through the whole busbar volume. This means that the current density can be much higher in some regions thus creating hot spots. In addition, these hot spots could induce mechanical stress able to promote cracks that finally results in the solar cell shunt. Several experiments and simulations demonstrate that solar cell degradation process starts with the GaInP top cell shunt followed by that of the $\mathrm{Ga}(\mathrm{In})$ As subcell.

In summary, this is the first time that a failure analysis is carried out after a temperature ALT showing that the failure origins are related to the electroplated front metallization as well as with the tab soldering process. Semiconductor structure does not seem to be the responsible of any failure. Therefore, this kind of lattice matched $\mathrm{GaInP} / \mathrm{Ga}(\mathrm{In}) \mathrm{As} / \mathrm{Ge}$ triple junction solar cells, that as of 2016, are the workhorse of CPV technology, come to light as very robust devices if the front metal connection is properly accomplished. It has to be highlighted that the results of this paper are applicable to the specific solar cells, assembled on the carriers in the specific way described in section 2. Accordingly, a generalization cannot be done to other solar cells assembled on different carriers.

\section{ACKNOWLEDGEMENTS}

This work has been supported by the Spanish MINECO through the projects TEC2014-54260-C3-1-P, -2-P and -3-P and by the Comunidad de Madrid through the project MADRID-PV (S2013/MAE-2780).

\section{REFERENCES}

1. Algora C, Rey-Stolle I. "Reliability", chapter 9 of the Handbook of Concentrator Photovoltaic Technology. John Wiley \& Sons Ltd: The Atrium, Southern Gate, Chichester, West Sussex, PO19 8SQ, UK, 2016.

2. Araki K, Al Taher O, Nagai H, Hebert P, Valles J. Are electro-luminescence defects in concentrator III-V cells responsible to thermal runaway and sudden death? in $7 T H$ International Conference On Concentrating Photovoltaic Systems: CPV-7, 2011, pp. 303306, DOI: $10.1063 / 1.3658349$.

3. Bosco N, Sweet C, Ludowise M, Kurtz S. An infant mortality study of III-V multijunction concentrator cells. Photovoltaics, IEEE Journal of 2012; 2: 411-416.

4. Bosco N, Kurtz S. CPV Cell Characterization Following One-Year Exposure in Golden, Colorado: Preprint. Golden, CO: National Renewable Energy Laboratory (NREL), 2014.

5. Espinet-González P, Algora C, Núñez N, Orlando V, Vázquez M, Bautista J, Araki K. Temperature accelerated life test on commercial concentrator III-V triple-junction solar cells and reliability analysis as a function of the operating temperature. Progress in Photovoltaics: Research and Applications 2014. DOI:10.1002/pip.2461.

6. Childs P, Greenwood J, Long C. Review of temperature measurement. Review of Scientific Instruments 2000; 71: 2959-2978. DOI:10.1063/ 1.1305516 .

7. Nuñez N, Vazquez M, Orlando V, Espinet-González $\mathrm{P}$, Algora C. Semi-quantitative temperature accelerated life test (ALT) for the reliability qualification of concentrator solar cells and cell on carriers. Progress in Photovoltaics: Research and Applications 2015; 23: 1857-1866. DOI:10.1002/Pip.2631.

8. Kwok R. XPS Peak Software. http://xpspeak.software. informer.com/4.1/

9. Tobin SP, Vernon SM, Bajgar C, Haven VE, Geoffroy LM, Sanfacon MM, Lillington DR, Hart RE, Emery 
KA, Matson RJ. High efficiency GaAs/Ge monolithic tandem solar cells. in Photovoltaic Specialists Conference, 1988., Conference Record of the Twentieth IEEE, 1988, pp. 405-410, DOI: 10.1109/ PVSC. 1988.105732.

10. Tautscher CJ. Contamination Effects on Electronic Products: a Basic Discussion of Common Contaminants, Their Origin, Effects, Removal, and Control, and Product Protection Against Contaminants from the u se Environment: $M$. Dekker, 1991.

11. Espinet-Gonzalez P, Romero R, Orlando V, Gabas M, Nunez N, Vazquez M, Palanco S, Bijani S, Contreras $\mathrm{Y}$, Galiana B, Algora C. Case study in failure analysis of accelerated life tests (ALT) on III-V commercial triple-junction concentrator solar cells, in Photovoltaic Specialists Conference (PVSC), 2013 IEEE 39th, Tampa, FL, 2013, pp. 1666-1671, DOI:10.1109/ PVSC. 2013.6744465.

12. Zimmermann C, Noemayr C, Kolb M, Rucki A. A mechanism of solar cell degradation in high intensity, high temperature space missions. Progress in Photovoltaics: Research and Applications 2013; 21 : 420-435. DOI:10.1002/pip.1195.

13. Barrigón E, Espinet-González P, Contreras Y, ReyStolle I. Why can't I measure the external quantum efficiency of the Ge subcell of my multijunction solar cell? AIP Conference Proceedings 2015; 1679: 050002. DOI:10.1063/1.4931523. 